\title{
Marriage and family metaphors in online Jordanian sociopolitical editorials
}

\author{
Mohammad Abedltif Albtoush \\ mohammad_albtoush76@yahoo.com \\ Universiti Malaya \\ Pei Soo Ang \\ angps@um.edu.my \\ Universiti Malaya
}

Abstract

Contextualized within corruption issues in Jordan, the Arab Spring uprisings as well as outsiders' padded relations and interests in the Arab region, this study explores how MARRIAGE and FAMILY metaphors construct the political reality of the partners involved. The integrative principles of the conceptual metaphor theory and critical metaphor analysis along with the concept of 'metaphor scenario' were applied to the data gathered from online Jordanian editorials published by Ahmad Al-Zu'bi (2010-2015). These metaphors were found in 97 out of 1000 editorials used in a larger study of different metaphors. Findings suggest the political relationships of the Arab rulers with the citizens and the outsiders are akin to marriage of convenience that violate the sociocultural traditions. Gender roles also appear to be tailored to the notion of masculine authority over femininity in so far as husbands' stubbornness or tenacity contributes to wives' zero-tolerance, hence the collapse of marriage and family system which is reflected on the ailing situation of the Jordanian sociopolitics. The key emotion of shaming permeates in 7 metaphorical scenarios: A stepmother scenario, illegitimate pregnancy, marriage proposal, dysfunctional family, parentless children, engagement, and married partners scenarios. Rhetorically, these scenarios serve as a call for principled relations between partners and emancipation of the passive Arabs from oppressing politics.

Keywords: metaphor, marriage, family, Jordan, critical metaphor analysis 


\section{Introduction}

The contemporary sociopolitical scene in Jordan and the Arab world has been fraught with tensed relationships between some Arab regimes and policy makers on one hand, and the passive subordinates on the other. In Jordan, this chaotic scene has been backdropped by the ailing problem of corruption highly contested by the public (Badarneh, 2020; Jackson, Tobin, \& Phillippa, 2019). Concurrently, the Arab uprisings set against some Arab regimes that sparked off in Tunisia (also known as the 'Arab Spring'), were also significantly triggered by corrupt political order (Kort, 2018). This scenario is further aggravated by the complex political relationships with Russia, America and Iran who have vested interests over political and economic dominance in the Arab region. Jordanians and Arabs have continuously been demanding for political and economic reforms, also social emancipation and democratic administrations (Chatti, 2020; Torlakova, 2014).

This critical state of affairs has been intensely debated in Jordanian news media (Albtoush, 2020; Fallah \& Moini, 2016). Disapproval and condemnation against the inefficient and corrupt Arab political practices are predominantly conveyed through the practice of shaming. Shaming in the Arab culture is a disparagement that connotes violation of norms, social and cultural value system (Al Jallad, 2010; Al-Uziazi, 2012). Specifically, a 4-time Jordanian writing award winner, Ahmad Hasan Al-Zu'bi, is highly critical of these on his news site (https://sawaleif.com/). Linguistically and stylistically, Al-Zu'bi's editorials are unique in that his condemnation through journalistic shaming are presented as satires with an extensive use of metaphors and metaphorical scenarios.

Linguistic studies on shaming and corrupt orders in the Arab world have been largely studied (Al Jallad, 2010; Badarneh, 2020; Kasasbeh, Mdanat, \& Khasawneh, 2018). However, specific critical studies of metaphorical language in Jordanian news media are limited to the political and economic discourses only. For instance, metaphors in political speeches of King Abdullah II (Abdulwahid, 2011; Al-Momani, 2017), metaphors addressing the Jordanian Monarch (El-Sharif, 2014) and metaphors in the Jordanian economic sphere (Zibin, 2018). Within a satirical sociopolitical context, metaphors are understudied. Therefore, Al-Zu'bi's journalistic choices offer engaging insights into the rhetorical aim and discursive implications of metaphors, different from those examined within other Jordanian news media discourses and thus, merit further investigations. 
In Al-Zu'bi's journalistic writing, the local and regional sociopolitical issues alongside the meddling from the outsiders in the Arab world have been discursively framed within universal and culturally-specific metaphors. Among the many types of metaphors discovered, the paper here focuses on the way the tangled relationships between the Arab regimes and successive Jordanian governments on one hand, and citizens on the other hand, are structured through MARRIAGE/FAMILY metaphors. It also focuses on how the relation-based interests in the Arab region between states/nations exemplified by America and Iran are shaped through metaphors drawing from MARRIAGE domain. This research will reveal what the rhetorical forces these selected metaphors communicate to the audience addressed, based on the perceptions and standards of Arabs' customs and traditions relating to the notions of marriage and family. While in literal terms, marriage is defined as a union of two people who are compatible with each other (Abdel-Raheem, 2020), the kind of marriage insinuated here appears to be a marriage of convenience based on exploiting weak citizens and states so that some Arab regimes could retain their powers. The representative MARRIAGE/FAMILY metaphors serve as a conduit for understanding the local cultural and cognitive aspects. Precisely, the paper asks the question of what and how the use of the MARRIAGE and/or rather the DYSFUNCTIONAL FAMILY metaphors in the editorials studied suggest about the current sociopolitical scenario in Jordan.

\section{Marriage/Family Metaphors in Political Discourse}

With the advent of the Conceptual Metaphor Theory (CMT) by Lakoff and Johnson (1980), structuring and perceiving the world around us has been delineated through the metaphors produced in our everyday speech. The CMT perceives metaphor as a cross-domain mapping within which our thoughts and reasoning about an abstract target domain are framed via an experientially concrete source domain. For example, the complex concept of POLITICS, can be simplified via the experiential source domain, MARRIAGE as shown in the pattern, POLITICAL COALITION IS A MARRIAGE (Đurović \& Silaski, 2010). Feinberg and Wehling (2018) also observed how familylevel beliefs turned into nation-level attitudes occur through the nation-as-family metaphor. Here, people's beliefs about ideal traits in children become ideal traits in citizens and their beliefs about ideal parenting are then mapped as beliefs about ideal governance.

Furthermore, Musolff (2006) found metaphor use in political discourse is rhetorically more effective at the specific scenario than at a domain-level. In a study performed on metaphor 
scenarios in public discourse on Brexit, Musolff (2017) found the European Union been metaphorically framed within a LOVE-MARRIAGE-FAMILY scenario. The political dispositions and ideological motivations within the discourse of Brexit become more discernible within mininarratives or scenarios.

Political dominance is also consolidated through manipulating the role of gender mapping within the use of MARRIAGE metaphors. Musolff highlighted that the Brexit SEPARATION/DIVORCE scenario unfolds the British and Germans' attitudinal biases and political preferences characterized by their male-centeredness. The political stances and power relationships of the British and Germans are premised upon their patriarchal traditions. Aljukić (2020) also recently elucidated that Britain's relationship and its separation from the EU is figured out through different creative metaphors such as STAGGERING and DYSFUNCTIONAL MARRIAGE which reaffirm Britain's political stance of being male-centred.

In the Asian context, Wee (2001) who addressed the merger and separation between Malaysia and Singapore found out that the mapping of the husband-and-wife roles in MARRIAGE metaphors by Malaysian and Singaporean politicians serves the political disposition of each country. The assigning of the husband role to Malaysia during the merger process was more flattering as it shows dominance; however, opting the wife role by Singaporean politicians serves their purpose in that the separation or divorce is beyond its responsibility relative to the Malaysia's political dominance. Similarly, Offiler (2020) who examined the MARRIAGE metaphors in the portrayal of the US-Iran relationships during the 1960s found masculinity is assigned to the US policy makers as husbands while the Shah/Iran is given feminine characteristics (i.e. a wife) indicating their weakness. Gender stereotyping within metaphors seems to be predominant across different political discourses.

The preceding reviews have paved way for the present work in so far as the notion of marriage encapsulates the idea of unequal power potentials. This idea prevails generally through the political attitudes and preferences of masculinity rather than femininity leading eventually to a dysfunctional family. However, the examined MARRIAGE/FAMILY metaphors in this paper are intended to further probe the role of shame in critiques of some Arab regimes and governments who fail in running their dependents. This failure is based on their clinging to power at the expense of the Islamic morals and Arabs' social values and norms whereby the infringement is highly sensitive to the culturally-specific emotion of shame (Al-Uziazi, 2012; Al Jallad, 2010). Similarly, 
manipulating relationships that are based on hypocrisy and duplicity between states conjures up an intense emotion of shaming from Arab sociocultural perspective.

\section{Methods}

The online news editorials analysed here were originally written in Arabic by a Jordanian columnist, Ahmad Hasan Al-Zu'bi on his satirical sociopolitical website. The data comprises 97 editorials out of a total of 1000 collected for a larger study on different metaphor types. They were sourced within the time frame of 2010 and 2015 as this time span is characterized by Jordanians' intolerance and protests against corruption and Arab Spring events.

We first applied the metaphor identification procedure (MIP) proposed by the Pragglejaz Group (2007) to identify the metaphor keywords based on the contrast between their contextual and basic meanings. The paragraphs containing the related metaphors were then translated into English. The accuracy of translation was checked by an American anthropologist who has good knowledge of Arabic and a follower of this news column.

The study is carried out within two integrationist approaches to metaphor: The CMT theory by Lakoff and Johnson (1980) and the critical metaphor analysis championed by Charteris-Black (2004). The CMT's premises hold that various linguistic metaphors are cognitively inferred by a concrete conceptual metaphor which, in turn, facilitates our understanding of a corresponding abstract target domain. For example, the conceptual metaphor pattern: LOVE IS A JOURNEY (Lakoff \& Johnson, 2003) is inferred by a number of surface linguistic metaphors such as: we are at $a$ crossroad; look how far we've come; this relationship is foundering; our marriage is on the rocks (p. 45). Following the CMT's tenets, the conceptual metaphor of MARRIAGE/FAMILY domains which are inferred by the identified linguistic metaphors, are mapped onto different abstract target domains; hence forming isomorphic relations between both domains as formulated by the conceptual pattern: X IS Y. However, since the MARRIAGE/FAMILY are the basic domains motivating a wider scope of generative potential sub-concepts, we classified the identified metaphor key words in the selected extracts under smaller sub-domains such as A STEP MOTHER, MARRIED PARTNERS and ENGAGEMENT which evoke more specific scenarios within these broad basic domains.

After elucidating the conceptual patterns and scenarios, we applied Charteris-Black's (2004, p. 29) critical approach to metaphor analysis "to make explicit political and ideological 
motivations that would, otherwise, be implicit or concealed". Within the CMA, Charteris-Black (2004) emphasized that the critical discourse of metaphor analysis is accounted for by integrating individual resources represented by cognitive affective, pragmatic, and linguistic criteria with social resources exemplified by ideology, culture and history. As such, investigating metaphors within media discourse makes an important aspect for the CMA in the sense that they are imbued with the rhetorical and ideological motives to be communicated to the addressed audience. Semino (2008) stressed the increasing role of culture in shaping discourses and therefore, the occurrence of linguistic metaphors and patterns is never innocent. Similarly, Charteris-Black (2004, p.251252) contended that "since metaphor is a way of creating cognitive and affective meaning, by changing the metaphor we may change the way that we think and feel about something", and "having the right to select our metaphors gives us the right to present alternative ways of thinking and feeling about the world".

Our analysis of the understudied metaphors is also based on Musolff's (2006) concept of 'metaphor scenario' which is regarded as one of the main framing devices in public discourse through which an organized packet of information relating to a specific aspect of experience such as our knowledge about actions, goals, entities, situations, and relationships are mentally projected on the target topic under discussion. On view of that, the analysis of the mini-narratives or scenarios of the Arabs' perspectives of marriage and family, and screening them onto the addressed target domains give us pivotal nodes of the rhetorical and cultural forces configured through these culturally-specific scenarios. With regard to the presentation style adopted in this paper, the metaphor key words are bolded, target domains are underlined, and the inferred conceptual metaphor patterns are presented in small uppercase letters.

\section{Analysis and Discussion}

In this section, only 7 representative identified scenarios relating to the notion of marriage/family are presented due to space limitation. The chosen exemplifications were based on what the researchers have found to carry intense emotion of shaming. The analysis of the broad MARRIAGE and FAMILY domains unfolds seven sub-domain metaphor scenarios: ILLEGITIMATE PREGNANCY, A STEP-MOTHER, MARRIAGE PROPOSAL, DYSFUNCTIONAL FAMILY, PARENTLESS CHILDREN, ENGAGEMENT, and finally MARRIED PARTNERS. 


\subsection{A Stepmother Scenario}

(1) Sweet... And Bitter!!

18 September 2014

The most suitable image describing the government is the 'father's [second] wife who has sharp eyes, a prominent hideous mole, and thick eyebrows... big nose and a special cane that she holds with hands threatening the innocent orphan son of her husband (the citizens) who does not find anyone to defend him in the absence of the father.

The discourse in (1) concerns the behaviour of the Jordanian officials who have long been rotating and occupying high positions in the state, yet unable to solve citizens' problems. Here, the negative attributes of a father's second wife metaphor are meant to depict governments' suppressing practices on the passive citizens within a satirical culture-specific mini-narrative, hence inferring the conceptual pattern, THE GOVERNMENT IS A CRUEL STEP-MOTHER. According to Islamic instructions, a man is allowed to marry at most four wives. In light of the partial mapping process, the government is personified in terms of a father's second wife replacing his deceased or divorced wife; the people are conceived in terms of innocent, passive orphans who are unable to defend themselves from their stepmothers. Also, the government's malpractice on citizens is structured in terms of the maltreatment orphans receive from their stepmothers. The mapping process reflects Jordanian traditional view of a stepmother who plays the dominant role in family affairs.

The choice of this metaphor originates from the cultural experiences of the Jordanian community whereby men's second wives (who replace the deceased/divorced first wives) are usually characterized by wickedness, a scary and ugly appearance such as sharp eyes, thick eyebrows, having a special cane and so on. The deceased wife's sons have become orphans and thus miss out the care and empathy that they used to receive from their birth mothers. The above negative associations of stepmothers are then projected onto the government, which is featured with negative attributes represented by debts, budget deficit, the imposition of taxes and soaring prices. Accordingly, the use of this novel metaphor symbolizes the government's cruelty, wickedness and shamelessness towards its citizens. It critically highlights how the break-up of family is reflected on the hostile relationship between successive governments and the helpless 
citizens, triggering the conceptual metaphors: THE GOVERNMENT IS ACTIVE and THE PEOPLE ARE PASSIVE.

Furthermore, if we consider the scenario as an "image schema", we must consider that the orientational metaphor UP and DOWN (Lakoff and Johnson, 1980) is captured by a stepmother's raising her hand over the orphans who symbolize POWERLESSNESS, inferring, thereby, the conceptual patterns: A STEPMOTHER IS UP, but ORPHANS ARE DOWN. Analogically, this orientational metaphor proposes that THE GOVERNMENT IS UP, but THE CITIZENS ARE DOWN. The shame of a stepmother is due to exercising her power and authority on the helpless orphans who miss the care from their birth mother. In the Jordanian folk literature, Al-Uziazi (2012) states that stepmothers' maltreatment of her husband's orphan kids away from people's eyes are shameful relative to her peaceful and down-to-earth appearance in front of the public. Thus, the above conceptual metaphors are tied to the higher key conceptual metaphor of: THE GOVERNMENT'S BEHAVIOUR IS A SHAMELESS STEP MOTHER'S BEHAVIOUR. Utilizing the brand-new metaphors above perform several functions, including the representational and 'ideational' ones (Halliday, 1978) where the very reality of the government's malpractice is structured in a more convincing manner through the use of a widely-understood source of oppression in the domestic sphere i.e. the unjust stepmother.

\subsection{Illegitimate Pregnancy Scenario}

\section{(2) Collusion}

23 December 2011

Corruption in our country is like an unmarried girl whose abdomen/stomach has swollen for nine months, with her parents indifferent toward her until she is due to give birth. At this point, the parents react in grief and anger. For 25 years, corruption is getting wider and wider with no care on the part of the government to abort it.

Within the FAMILY domain, the most intense emotion of shame is inspired through personifying CORRUPTION in terms of an ILLEGITIMATE CHILD as seen in (2). The context of the columnist's chosen metaphors is inspired by the luxurious palaces belonging to corrupters who siphoned the country's wealth but left unpunished. By framing corruption in terms of ILLEGITIMATE PREGNANCY 
is entirely against Islamic rules and Arabs' sociocultural value system, leading thereby the columnist to rhetorically shame the act of corruption.

The country corresponds to a girl; corruptors are those who seduce the girl and corruption is the illegitimate pregnancy. Here, we can infer the conceptual metaphors: THE ACT OF CORRUPTION IS SEDUCTION, and CORRUPTION IS A BASTARD. In this context, seduction seems to be more apt than rape as it implies attractiveness and temptation by a girl who alongside her parents kept silent and indifferent until it is due time to give birth as shown by her parents' observation for nine months. Raping would have suggested a girl's prompt resentment, demanding an immediate action by the parents. Thus, in this context, seduction suggests that the embezzlement and siphoning of citizens' wealth are within the reach of the corrupters.

The scenario, at this juncture, holds that the parents of the girl have observed their daughter's pregnancy from the time her abdomen began to swell until she delivered the bastard. For over the nine months of pregnancy, the parents were indifferent about this shameful and scandalous act, but when it is time to deliver the child, the parents were full of rage and grief towards their daughter. The material of this source domain is analogically mapped onto the sociopolitical problem of corruption. Here, we mean the concrete actions of sexual intercourses or seducing a girl over a long time are partially screened into the various forms of corruption exemplified by embezzlement and siphoning of public wealth across decades. Nine months of sexual intercourse do not imply corresponding nine others of corruption, but this is because this period is the maximum duration for giving birth. As such, the act of corruption is an abstract concept which is not governed by time.

The government has long observed how the country's wealth and national companies are embezzled along with other various forms of corruption such as social injustice and cronyism. However, instead of aborting the illegitimate pregnancy in its early stages, the government has been indifferent about corruption until it reaches a climax, and thereby it is impossible to drastically eradicate this chronic phenomenon. This metaphoric scenario attends to the proverb that reads as: prevention is better than cure. The metaphorical expressions above provide evidence for the following conceptualization: CORRUPTION IS A SHAME or A SCANDAL. This is because committing scandalous acts as such is regarded as an everlasting stigma or slap on the face of the whole family (Al Jallad, 2010).

\subsection{Marriage Proposal Scenario}


3) Following Jolie's Way

2 September 2014

Politically... what if the nations built a trial dating relationship with some Arab regimes for some years as a trial relationship like Brad Pitt and Angelina Jolie... If they agreed they would continue and the relationship would be constitutionally confirmed. If they differed, "everyone would go their own way". The peoples have become disgusted with "surprise marriage" where the engagement contract is signed for her in a day and a night... We are not suited for "child marriage".

The context of inspiring MARRIAGE sub-domain metaphors in (3) is attributed to Arab uprisings or the so-called 'Arab Spring'. This represents a novel conceptual metaphor by the columnist to negatively structure the relationship between Arab regimes and citizens. Thus, these metaphors are surface linguistic realizations of the conceptual metaphors: ARAB REGIMES-CITIZENS' UNIFICATION IS A MARRIAGE and ARAB REGIMES-CITIZENS' SEPARATION IS A DIVORCE. The columnist's particular choice of this metaphor type is intended to shed light on power and gendered sociocultural reality of marriage in the Jordanian community and hence mapping them onto the political target domain.

Based on the partial mapping process, it is apparent that the highlighted conceptual makeup elements between MARRIAGE source domain and the RELATIONSHIP BETWEEN ARAB REGIMES and CITIZENS target domain are activated through the idea that Arab regimes correspond to a husband as they have authority over citizens; Arab people correspond to a wife as they are run by regimes; harmony between regimes and peoples corresponds to a husband-wife unification, and finally disharmony between regimes and peoples corresponds to husband-wife divorce. According to Lakoff and Johnson (1980), the marriage metaphor scenario is usually associated with the complex journey metaphor scenario to indicate either marriage-free impediments and hence maintaining a harmonious relationship and continuity between the married couples, or marriageencountered obstacles, yet resulting in a disharmonious relationship (i.e., divorce) between the married couples.

This satirical scenario evoked by marriage metaphors suggests that Arab regimes should consider the form of the previously literal marriage between American celebrities Brad Pitt and Angelina Jolie as role models. Put simply, the couples had their children during ten years of 
developing a deeper understanding of each other's temperaments before officially being married. Though this western marriage type is unacceptable from the perspectives of Islam and Arab sociocultural traditions, the columnist emphasizes the notion of taking a longer duration of wisdom and calculations in order for couples to get on well with each other before a marriage decision. This ultimately implies a successful marriage of equals between the husband and wife as far as dominance and independence are concerned. Here, a successful marriage can be grasped through the different phases of the experiential JOURNEY conceptual metaphor exemplified by engagement period and the marriage one. The American celebrities' marriage suggests a long pre-marriage phase in which the couples have children and at later stage they decided to get married with the result that their marriage has become a success. In contrast, the customary Arab marriage starts with the engagement period during which fiancés usually spend a year to understand each other before the subsequent marriage phase, suggesting that the engagement phase should be a determining factor for marriage continuity or discontinuity.

These two-marriage types suggest that REGIMES-CITIZENS' UNIFICATION IN THE WEST IS A SUCCESSFUL MARRIAGE, but REGIMES-CITIZENS' DISUNIFICATION IN THE ARAB WORLD IS A FAILING MARRIAGE. Within the context of this study, the implicit message of the columnist's metaphors is to emphasize the success of the Western regimes in managing their citizens relative to the Arab regimes which have been toppled by their oppressed citizens. Screening the two-marriage scenarios onto the political target situation unfolds into two corresponding political scenarios: a successful political management in the West, but a failing political management in the Arab world. The columnist's metaphorical expressions of 'surprise marriage' and 'child marriage' poke fun of Arab political management of Arab people through the fact that a sudden marriage decision and allowing an immature underaged to marry will no longer be successful. As in the first case, this fateful decision is executed within a short time and eventually the marriage becomes a complete failure. In effect, Al-Uziazi (2012) emphasizes that only men could bear the expenses of their families. Ontologically, corrupt Arab regimes are shaped through this two-husband type and Arab people are understood in terms of a wife, yet the familial relationship will be a fragile one as long as the former are no longer able to sponsor the latter, resulting in a complete marriage failure. This is exemplified by the notion of 'Arab Spring' whereby some Arab regimes fall short in running their peoples leading finally to revolutions against them. 
From critical discourse perspective, the columnist's use of marriage metaphors asserts the social concept of 'maleness' in the Arab world. This male-dominance concept is religiously motivated in the noble Hadith, but it highlights a married life that is based on justice and respect. More importantly, the complex journey-marriage scenarios crystalize the idea of 'failure' which is in turn closely connected with the embedded key metaphor of SHAMING some Arab regimes that lag behind managing their dependents wisely. Thus, along with their cognitive and humorous functions, marriage metaphors serve a rhetorical effect to call for abolishing the stubbornness of Arab regimes and maintaining an equal weight between Arab regimes and their dependents.

\subsection{Dysfunctional Family Scenario}

\section{4) Arab Sharia Court \\ 7 July 2013}

I do not know why the whole Arab world has turned into a big Sharia Court [family court]......peoples divorce their regimes, regimes get engaged with other peoples, and regimes demand "maintenance" from peoples.....leaderships were in a hurry asking for the departure of their regimes and soon began "receiving inheritance"... and other leaders asked for a "fatwa [an Islamic legal opinion]" for halal [lawful] reunions [of previously estranged spouses], peoples divorced their regimes due to the impossibility of life between them...then announced that they were signing a new contract (with a new contract and bride wealth)...... Politics in the Arab world is metaphorically speaking "Sharia Court procedures"...both the groom and the divorcee pay the marriage fees .....Nobody is benefiting except... the stamp-seller.

Humorous marriage metaphors in (4) depict the Arab situation during the so-called 'Arab Spring' within a much real-life scenario where Arab regimes-citizens' relationship is shaped in terms of a husband-wife union, intrinsic to Islamic-Arab culture. The bolded metaphoric expressions embed the previous conceptual metaphors: ARAB REGIMES-CITIZENS' UNIFICATION IS MARRIAGE, whereas ARAB REGIMES-CITIZENS' SEPARATION IS DIVORCE. Based on these metaphor themes, Arab countries are described in terms of Sharia courts; Arab regimes correspond to a husband; Arab citizens to a wife, unification/separation between Arab regimes and their dependents in the Arab world are framed in terms of marriage/divorce procedures at sharia court; and finally meddling 
international powers are conceived in terms of the beneficiary stamp-seller. It should be pointed out that Arab regimes are conceptualized in terms of a husband because they have authority/power upon their dependents from sociocultural perspective (Al-Uziazi, 2012). Men are usually the sponsors of their wives and dependents, and they run their family errands in Arab culture. Also, in the Holy Qur'an (Surah, An-Nisa /women: verse, 34) men are the rulers/guardians who are in charge of women and bear his family responsibility.

The highlighted conceptual elements above inspire a mocking scenario criticizing the predominant tension between some Arab regimes and citizens. In effect, the concrete MARRIAGE/DIVORCE scenario envisions a range of SHAMEFUL encounters in the sharia court, a place that is integral to the regulation of an Islamic community. While relationships among family members should be generous and unselfish, the columnist projects a scenario in which the worst motives in the Sharia court map onto the relationship between peoples and governments in the Arab Spring. These motives are exemplified by five kinds of Sharia court controversy: divorce, remarriage, demanding maintenance, being in a hurry for parents to get their inheritance, and marrying the same person again. According to Zahran, Al Heiajnh, and Abu Jelban (2015), divorce in Jordan often occurs because of reasons such as tensions attributed to age range between a husband and wife, and hence a lack of thought match between them, mis-selection, lack of responsibility, costly-living expenses and infidelity. Secondly, remarriage takes place when the husband divorces the wife completely and hence the latter gets married to a new person. However, the third case is concerned with a husband who has separated from his wife, with the wife going back to her parents' house and demanding alimony or maintenance from the husband as she is not divorced yet. The fourth type happens in cases of death to either the husband or wife. The parents of both husband and wife have their own rights to receive part of their son or daughter's inheritance. Finally, marrying the same person again is what happens when there is a husbandwife reconciliation, but this is conditioned by the number of times a husband divorces his wife. The worst case of all is the third-divorce utterance whereby the husband has to sign a new-marriage contract and pay a new dowry to the wife.

From Jordan's socio-cultural perspective, Al-Uziazi (2012) contends that marriage is usually conditioned by the couples' approval; however, in some cases it is unimportant to get the girl's approval. This, again, highlights the fact that marriage in Arab culture is marked by 'male dominance and power' over powerless femaleness whereby men are responsible for living 
expenses of their families as well as being decision makers such as divorcing their wives (AlUziazi, 2012).

Screening the above concrete MARRIAGE/DIVORCE narratives onto the chaotic sociopolitical situation of countries experiencing 'The Arab Spring', this implies either a replacement of some former Arab regimes by new current ones, or governments' exploitation of their dependents. For instance, the peoples of Tunisia, Yemen, Egypt, Libya and Syria have revolted against their former corrupt regimes, questing for overall reform and social equity. This act of distrust is SHAMING the leaders for their incompetence and FAILURE to manage their dependents justly. Secondly, these Arab countries as well as Iraq have been ruled by newly appointed governments and regimes whereas Syria is ruled by Russia and Iran.

The third case of MARRIAGE/DIVORCE scenario above is mapped onto the tense relationship between governments and citizens. The successive governments of Jordan impose high taxes on citizens such that citizens have become governments' sponsors. The fourth divorce case refers to the Iraqi situation in which the Shiite sect received the wealth that is left from the former regime of Saddam Hussein. Finally, the re-election of the Syrian president Bashar Al-Assad that was imposed upon the Syrian citizens under duress in the midst of a Civil War accounts for signing a new marriage contract and bride wealth according to Islamic law.

More significantly, shaming a dysfunctional family is captured through different encounters of marriage and divorce between the couples. This emotion of shaming the Arabs becomes apparent when comparing the situation of Arab Muslim countries which should adhere to the permanency of family system which Arabs usually cherish; however, having these encounters is shameful to Arab regimes which have been made fun of in comparison to non-Muslim just regimes in other parts of the world. The art of satire used by the columnist accentuates that family metaphors are veritable means to attack the deficiencies, vices, and follies of politicians and regimes which have been stamped with a disreputable outlook locally and internationally within a shameful funny manner. For instance, the element of humor prevails through demoting the relationships between Arab regimes and citizens to a husband-wife clashes as well as through conceptualizing the meddling outsider in terms of a stamp-seller who usually sells stamps for the couple's marriage contracts at the gate of Sharia court and gains/accumulates money from those couples whose marriage turns out into a complete failure. 
The above discourse highlights the widespread corruption problem in the Arab world typified by embezzlement, siphoning public wealth and subjecting people to abject poverty are captured in terms of 'infidelity' which makes husband-wife unification impossible. Critically speaking, the use of DIVORCE metaphors emphasizes the ideological SHAMING of the tyrannical regimes which have failed to manage their dependents and SHAMES the Arabs generally as they are the losers who let global powers meddle in their countries to achieve their agenda.

\subsection{Parentless Children Scenario}

(5) Decorative String

10 April 2015

We are an orphan nation.... who sleep upon the order of the western nanny (America) and wake up on the voice of the eastern nanny (Russia)...? They divide us up like a duty and distribute us by lot....

Metaphor key words in (5), and (6) below address the whole Arabs and they can be collectively referred to as 'confinement metaphors' signifying humiliation and imprisonment as they portray the afflicted Arab people in terms of little children being cut off from their family and human mercifulness and care, as well as innocent inmates banned from gaining their own rights and freedom as in (6) below. All in all, the columnist's metaphors do agree on a common ground emphasizing a disgraceful metaphoric image about the PASSIVITY/ INFERIORITY of all Arabs, yet implicitly confirming the ACTIVITY/ SUPERIORITY of global powers. These conflicting notions attend to the orientational metaphor type: INFERIORITY IS DOWN, but SUPERIORITY IS UP. In the light of this parentless children metaphor, two dyadic metaphor patterns are inferred: ARAB PEOPLE ARE ORPHANS, and AMERICA AND RUSSIA ARE NANNIES. The columnist's metaphors explicitly envision a sorrowful indignation tone against Arabs' current situation; it is a complete SHAME in that some Arab regimes have been demolished leaving chaos and wars behind. In the source domain, 'orphans' refer to little children/minors who are cut off from the care customarily given to them by their parents, but due to the latter's absence or death, orphans' care is usually assigned to their next of kin represented mainly by the step mother and aunts respectively (Al-Uziazi, 2012).

However, Al-Uziazi asserts that the care given to orphans by these two caregivers is a suppressing and unjust one in the Jordanian community in which the extreme vulnerability and 
oppression of orphans have become an archetypical proverb in Jordan heritage being exemplified by 'The hospitality of Hasan's aunt'. The proverb implies that Hasan, the orphan, has escaped from his stepmother's ill treatment to feel secure at his aunt's house. However, the aunt enslaves him to look after goats with no payment and she even advises him to eat from pastures. The punishment to caregivers who mistreat orphans is reflected in the Holy Koran through the verse 'Verily, those who unjustly eat up the property of orphans, they eat up only a fire into their bellies, and they will be burnt in the blazing fire' (Surah An-Nisa, 4:10). It is clearly shown that religious and social resources propagate the need to be merciful and supportive to orphans.

Projecting this metaphor scenario onto Arabs' current situation suggests an extreme humiliation and hegemony practiced by the two global powers of America and Russia (the 'nannies') on Arab people the 'orphans'. The columnist highlights the Arab world is run by these two global powers particularly in Syria and Iraq and the wealth of the Arab is eaten up by these guardian powers. These creative metaphors imbue a pathetic metaphor tone of Arab's humiliation which in turn exerts the ideology of SHAME as a higher-level metaphor represented by: GLOBAL POWERS' HUMILIATING AND ENSLAVING OF ARAB PEOPLE IS A SHAME. Simultaneously, SHAMING the Arabs is intended to wake up them from their passivity and confront global powers' intervention in their internal affairs.

\subsection{Engagement Scenario}

(6) Political Engagement

28 January 2014

America and Iran are passing these days... in the stage of political engagement in the full sense of the word. Both of them want to see the best of what the other has to offer in terms of good intentions, treatment and unprecedented understanding.

The columnist's use of MARRIAGE metaphors in structuring America-Iran relationships unmasks common social values that are SHAMEFUL in the Jordanian community: hypocrisy and duplicity. Engagement - a phase prior to marriage in the Arab culture and Jordanian community is commonly characterized by smooth relationship and countless fruitful promises initiated by the fiancé towards his fiancée. However, this kind of stereotypical relationship turns out to be unlike the one during 
the subsequent marriage stage as the true picture of the fiancé, in terms of escaping his fake promises, become apparent to his fiancée, and that his agenda is to gain benefit from the fiancée rather than the other way round. It has been mentioned earlier in (3) that in the Jordanian community, the engagement phase is a prerequisite short-term journey which is ideally characterized as an obstacle-free one so that the couple could achieve their goal: marriage. Nevertheless, because the subsequent marriage phase is a long-term journey, it is more likely that the couple's concealed intentions in the first period will be revealed, yet causing problems which could lead to divorce.

Projecting the engagement tangible scene onto the political target domain proposes two novel conceptual metaphors: AMERICA-IRAN'S POLITICAL CONVERGENCE IS ENGAGEMENT and AMERICA-IRAN'S POLITICAL UNIFICATION IS HUSBAND-WIFE UNION. The conceptual mapped elements which activate these metaphor patterns can be understood through the idea that America corresponds to a fiancé and Iran to a fiancée; America-Iran's initial cordiality is shaped in terms of the fiancé's-fiancée's fake love during the engagement period. However, within the marriage period, America's political agenda aiming at Iran's nuclear disarmament correspond to the husband's agendas of exploiting his wife during their marital life. Based on these correspondences, the ENGAGEMENT/MARRIAGE scenarios are mixed up with two phases of the JOURNEY scene which in turn unravel common social ills represented by duplicity, flattering, and cheating.

From critical discourse perspective, the columnist's metaphors perform a humorous function in that the leading position of politics is downgraded into a duplicitous marriage. They also point to underlying ideological statement about the nature of POWER in that America considers Iran to be its rival power and fears that it might one day have nuclear weapons that might threat the former's interests in the Middle East. Based on this ideology, the columnist's metaphors highlight their rhetorical function of exemplifying America's manipulative strategies aiming at Iran's nuclear disarmament. As such, it can be inferred that America's hidden agenda towards Iran are better accounted for by Machiavelli's assumption: ‘the ends justify the means’ (Ascoli \& Kanh, 1993). 


\subsection{Married partners scenario}

\section{(7) Now Connected \\ 24 April 2014}

Even complicated politics in the region can be considered as marital problems, but on a larger scale. The tenets are the same: boundaries, influence, interests, economy, negotiation, reconciliation, or conflict. What happened between America and Iran in terms of mutual understanding, far from that of the "Arabs," and far from the good will initiatives and emissaries... is a perfect return to normal marital life with no mediation.

The columnist also utilizes novel metaphoric expressions drawing from the MARRIAGE source domain to depict the dyadic political encounters between America and Iran in the Arab region. These bolded metaphors, thus, suggest the conceptual metaphor pattern: AMERICAN-IRANIAN POLITICAL UNIFICATION IS MARRIAGE, which is activated via a set of conceptual elements. For example, America corresponds to a husband and Iran to a wife; political interests are shaped in terms of married couples' interests; their political union is conceived in terms of harmonious marital life and finally; and their political differences are framed in terms of disharmonious marital life.

According to Zahran et al. (2015), there has been a marriage trend in the Jordanian community where the youth prefer to marry an employed wife rather than a jobless one to overcome poverty. This trend explains that marriage is based on materialism and not on genuine love between the couples with the result that the continuation of their marriage is liable to obstacles. To this effect, marital life in the Jordanian community is usually vulnerable to common problems related to the husband's individualism in making decisions exemplified by favouring his own interests over the wife's; yet disregarding the latter from proposing her opinion as a co-partner in the marital life. Moreover, the idea of gender is emphasized in the Holy Koran as in 'men are the protectors and maintainers of women' (Chapter 4, the women, Verse 34). However, this idea of favouring maleness over femaleness in the Holy Koran is attributed to men's strength to protect women's rights rather than to dominate them. Similarly, though Jordan community is male-based, Al-Uziazi (2012) states that wives have their own rights and dignity such that the husband should consider his mother's opinion first and the wife's opinion only then. That is, husbands should not 
be stubborn and have individualized decisions, rather they usually share their decisions with their parents and wives suggesting that marriage life be based on mutual respect between the married partners. Nevertheless, the husband-wife disagreement is usually concerned with the common cultural belief that husband's manhood is proven by the husband's stubborn need to be the ruler of the whole family.

Mapping the above scenario onto American-Iranian political relationship suggests mixing up a temporary JOURNEY scenario in that the two-power's unification is conditioned by America's materialistic interests and achieving its political agenda rather than by a genuine friendship. Considering the explanatory phase of the critical metaphor analysis, the columnist's metaphors within the MARRIAGE-JOURNEY scenario embed the rhetorical insight of SHAMING the fragile political journey between America and Iran, which often ends up in complete failure. Thus, the scenario imbues the thoughts of its readership with a SHAME emotion through the conceptual metaphor: POLITICS-BASED INTERESTS ARE MARRIAGE-BASED INTERESTS.

More significantly, the columnist's discourse on the exclusion of Arabs from AmericaIranian relationship implicitly suggests the idea that the Arab countries, though rich, are framed in terms of a rejected girl by America only because they are powerless and hence, they can be attained anytime. Contrastively, Iran is shaped in terms of America's object of desire because it is a threatening Middle Eastern power which has been meddling into Arab countries such as Iraq, Syria, Yemen and Lebanon with the result that it may affect America's interests in these countries.

In the concrete marriage scenario, the husband-wife's frequent encounters represented by marriage, fight and reconciliation are SHAMEFUL for both parties. Ontologically, these different encounters are captured in the American-Iranian relationship suggesting that their overly-public seduction, fight and reconciliation are main sources of SHAME.

\section{Conclusion}

Metaphor scholars such as Charteris-Black (2004, 2005) and Musolff (2006, 2017) emphasized that selecting metaphors in a particular discourse community is increasingly tailored to the cognitive, affective and rhetorical forces shaping our thinking and feelings about that community. According to Dueck (2001, p. 369), the particular selection of MARRIAGE metaphor serves as an appropriate cognitive option by individual speakers to "create images of political reality". On view of that, the analysis of the current sociopolitical issues in Jordan and the Arab world, and the 
outsider's meddling into the Arab region along with American-Iran relations has shown that the different metaphor scenarios evoked by the broad conceptual metaphor, MARRIAGE/FAMILY are tied up with the Arabs' culturally-specific emotion of shaming. Indeed, this emotion of shaming appears to be evoked through statical scenarios through which the Arabs are demoted into downgraded positions as they are unable to manage themselves. This main finding is set against the scenario of dysfunctional family where its creation is based on a marriage of convenience, references to dominant power, infidelity and breaking-up of sociocultural traditions and norms, rather than one based on love and intimacy. It is also shown that male-centredness is the governing stereotyping attitude throughout the different scenarios analysed, echoing thereby the longstanding patriarchal tradition of the notion of marriage/family in the Arab culture. However, in the Arab family system, the stereotyped 'stepmother' could also be the dominant partners who could shake a family. With the exception of the stepmother metaphor, the gender relations here provide a model which appears to be working through the majority of marriage and family metaphors in so far as how to deal with unequal power relations while abiding by the Islamic morals and Arab social ethics. Rhetorically, the examined metaphors serve as a wake-up call for Arab regimes, governments, and policy makers to reconsider their relationships with each other and their citizens.

\section{Acknowledgement}

The authors would like to thank Dr Geoffrey Hughes for his contributions in this research.

\section{References}

Abdel-Raheem, A. (2020). Moral metaphor and gender in Arab visual culture: Debunking Western myths. Social Semiotics, 30(5), 715-742.

Abdulwahid, H.Y. (2011). Metaphors and their morality implications in political speeches: A pragmatic study. Journal of College of Education, 4, 843-867.

Albtoush, M. (2020). Metaphors of political satire: A study of online Jordanian news columns. (Doctoral). Universiti Malaya, Kuala Lumpur. 
Al Jallad, N. (2010). The concept of shame in Arabic: Bilingual dictionaries and the challenge of defining culture-based emotions. Language Design : Journal of Ttheoretical and Experimental Linguistics, 12, 31-57.

Aljukić, L. (2020). Metaphorical creativity in British political discourse on Brexit. (Doctoral). Josip Juraj Strossmayer University of Osijek, Croatia.

Al-Momani, H. (2017). Political discourse of Jordan: A critical discourse analysis International Journal of English Linguistics, 7, 90-98.

Al-Uziazi, R. (2012). Ma'lamat at-turath al-aurduni, The Jordanian folk literature (Part 1). Amman, Jordan: The Ministry of Culture.

Ascoli, A. R. \& Kahn, V. A. (1993). Machiavelli and the Discourse of Literature. Ithaca: Cornell Univ Press.

Badarneh, M. A. (2020). Discourses of defense: Self and other positioning in public responses to accusations of corruption in Jordan. Discourse Studies, 22(4), 399-417. doi:10.1177/1461445620914670

Charteris-Black, J. (2004). Corpus approaches to critical metaphor analysis. New York: Palgrave Macmillan.

Charteris-Black, J. (2005). Politics and rhetoric: The persuasive power of the metaphor. London: Palgrave Macmillan.

Chatti, S. (2020). Seasonal metaphors in Arab journalistic discourse. Metaphor and the Social World, 10(1), 22-44.

Dueck, C. (2001). Gendered Germanies: The fetters of a metaphorical marriage. German Life and Letters, 54(4), 366-376. doi:10.1111/1468-0483.00210

Đurović, T., \& Silaski, N. D. (2010). Metaphors we vote by: The case of 'marriage' in contemporary Serbian political discourse. Journal of Language and Politics, 9(2), 237259.

El-Sharif, A. (2014). Anti-coercion function of metaphors in Jordanian media discourse. International Journal of Humanities and Social Science, 4(4), 138-148.

Fallah, N., \& Moini, M.R. (2016). A critical metaphor analysis of Arab uprisings in "The Washington Post" and "Keyhan" editorials. Metaphor and the Social World, 6(1), 79-102.

Feinberg, M., \& Wehling, E. (2018). A moral house divided: How idealized family models impact political cognition. PloS One, 13(4). doi:10.1371/journal.pone.0193347 
Halliday, M. A. K. (1978). Language as social semiotic: The social interpretation of language and meaning. London: Edward Arnold.

Jackson, D., Tobin, S., \& Phillippa, E. J. (2019). Capacity building for politicians in contexts of systemic corruption: Countering 'wasta' in Jordan. Norway: CHR Michelsen Institute.

Kasasbeh, H. A., Mdanat, M. F., \& Khasawneh, R. (2018). Corruption and FDI inflows: Evidence from a small developing economy. Asian Economic and Financial Review, 8(8), 10751085.

Kort, S. (2018). Metaphor in media discourse: Representations of 'Arabs' and 'Americans' in American and Arab news media (Doctoral). University of the West of England, United Kingdom.

Lakoff, G., \& Johnson, M. (1980, 2003). Metaphors we live by. Chicago: University of Chicago Press.

Musolff, A. (2006). Metaphor scenarios in public discourse. Metaphor and Symbol, 21(1), 23-38.

Musolff, A. (2017). Truths, lies and figurative scenarios: Metaphors at the heart of Brexit. Journal of Language and Politics, 16(5), 641-657.

Offiler, B. (2020). 'Marriage', 'massage', metaphor and gender in US-Iranian relations during the 1960s. The International History Review, 42(1), 117-132.

Pragglejaz Group. (2007). MIP: A method for identifying metaphorically used words in discourse. Metaphor and Symbol, 22(1), 1-39.

Semino, E. (2008). Metaphor in discourse. Cambridge: Cambridge University Press.

Torlakova, L. (2014). Metaphors of the Arab Spring: Figurative construals of the uprisings and revolutions. Journal of Arabic and Islamic Studies, 1(14), 1-25.

Wee, L. (2001). Divorce before marriage in the Singapore-Malaysia relationship: The invariance principle at work. Discourse \& Society, 12(4), 535-549.

Zahran, Y. M., Al Heiajnh, W. S., \& Abu Jelban, O. M. (2015). Reasons behind divorce in Jordan and its educational implications. Journal of Al-Quds Open University for Educational \& Psychological Research \& Studies, 3(11).

Zibin, A. (2018). The effect of the Arab Spring on the use of metaphor and metonymy in Jordanian economic discourse: A cognitive approach. Review of Cognitive Linguistics. Published under the auspices of the Spanish Cognitive Linguistics Association, 16(1), 254-298. 